\title{
Hand Sanitizer: A Savoir or Poison
}

\author{
Satesh Kumar* \\ $4^{\text {th }}$ year MBBS student, Shaheed Mohtarma Benazir Bhutto Medical College Liyari, Pakistan \\ *Corresponding author: Satesh Kumar, $4^{\text {th }}$ year MBBS student, Shaheed Mohtarma Benazir Bhutto Medical College Liyari, \\ Karachi, Pakistan
}

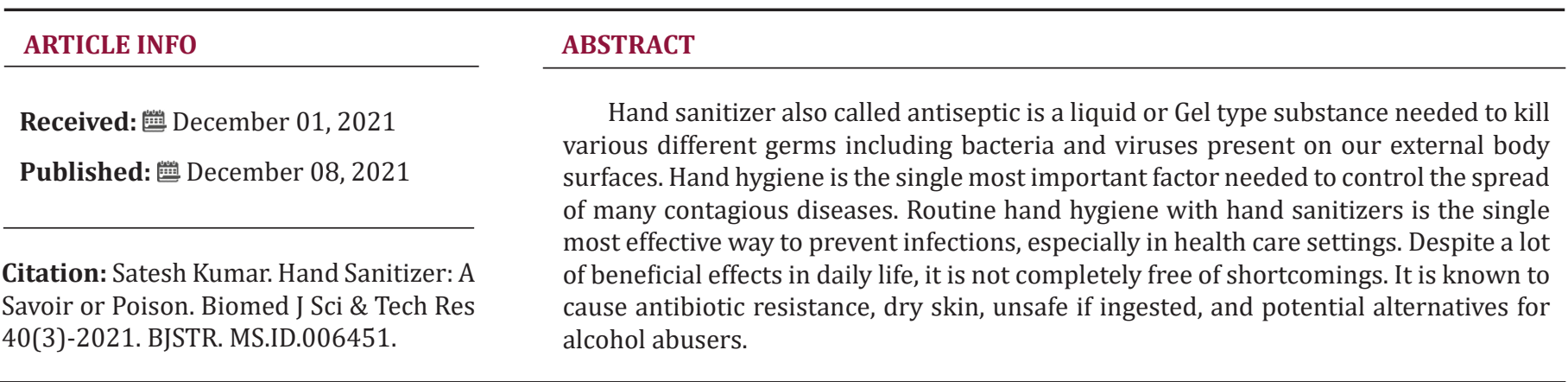

\section{Editorial}

Infectious diseases can spread from one person to another with contaminated hands. Therefore, Hand hygiene is one of the most important things needed today to prevent the spread of infectious diseases such as viruses or bacteria. The most widely used methods to prevent these infections are washing hands with soap and water or using alcohol-based sanitizers. Sanitizers may vary in their composition. According to World Health Organization [1], alcoholbased sanitizers are most effective compared to other methods of hand hygiene. Two formulations have been suggested to locally produce these products. One formulation includes (ethanol $96 \%$, hydrogen peroxide $3 \%$, glycerol $98 \%$, and sterile distilled or boiled cold water) and formulation includes (Isopropyl alcohol 99.8\%, hydrogen peroxide $3 \%$, glycerol $98 \%$, and sterile distilled or boiled cold water). Due to the presence of a significant amount of alcohol, these may be used as a substitute by alcohol abusers.

In accordance with the Centers for Disease Control and Prevention, alcohol-based sanitizers are only effective if they contain at least $60 \%$ alcohol [2]. A 2013 study suggested; for highrisk individuals, ethanol-based sanitizers may be a substance of abuse and their access should be limited. However ethanolbased sanitizers were not considered as primary alternatives in alcoholics [3]. A 2015 study reported 385 total cases of hand sanitizer ingestion; 61\% unintentional, 18\% intentional misuse, and $10 \%$ miscellaneous. Most of them were younger males (potent abusers). However serious outcomes were not reported and cases were managed favorably [4]. In 2019 a case was reported in the New England Journal of Medicine, in which a 54-year-old man undergoing alcohol withdrawal ingested hand sanitizer (which contained $63 \%$ isopropanol) had access to hand sanitizer at his bedside which is commonly provided in health care settings for hygiene purposes [5].

In 2021 another case in Cureus journal was reported in which a 30-year-old male patient with alcohol use disorder was found intoxicated who was subsequently owning several bottles of sanitizers which gave a clue of his potential intoxication and withdrawal symptoms later. Therefore possible intervention should be applied in using these alcohol-based products in health care settings and their use should be limited for potential abusers. Hand sanitizers are the preferred way of protecting ourselves from the spread of such contagious diseases but steps should be taken to minimize their use as the potential choice of abuse. Washing hands with soap and water is the best alternative available for potential abusers as well as in health care settings. 


\section{Declarations}

All manuscripts must contain the following sections under the heading 'Declarations':

- Ethics approval and consent to participate: Not applicable

- Consent for publication: Not applicable

- Availability of data and materials: Not applicable

- $\quad$ Competing interests: Not applicable

- $\quad$ Funding: Not applicable

- Authors' contributions: Data collection, literature review, manuscript writing

- Acknowledgement: Not applicable.

ISSN: 2574-1241

DOI: $10.26717 /$ BJSTR.2021.40.006451

Satesh Kumar. Biomed J Sci \& Tech Res

(c) (P) This work is licensed under Creative

Submission Link: https://biomedres.us/submit-manuscript.php

\section{References}

1. (2009) World Health Organization. WHO guidelines on hand hygiene in health care Accessed.

2. Jones R, Schuhmann L, El-Mallakh R (2013) A patient who prefers to imbibe ethanol-based hand sanitizer over traditional alcoholic beverages. Am J Addict 22(2): 148-149.

3. Forrester MB (2014) Characteristics of hand sanitizer ingestions by adolescents reported to poison centers. Int J Adolesc Med Health 27(1): 69-72.

4. Fenves AZ, Mojtahed A, Nisavic M, Massoth LR (2019) Case 13-2019: A 54-Year-Old Man with Alcohol Withdrawal and Altered Mental Status. N Engl J Med 380(17): 1657-1665.

5. Pourmand A, Ghassemi M, Frasure SE, Robert Shesser (2021) Hand Sanitizer Intoxication in the Emergency Department. Cureus 13(9): e17906.

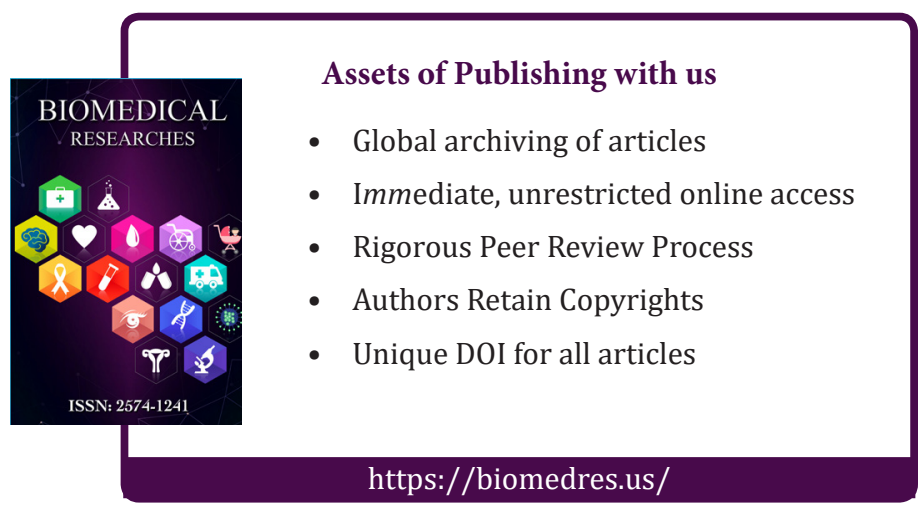

